\title{
Allogeneic Blood Product Donation
}

National Cancer Institute

\section{Source}

National Cancer Institute. Allogeneic Blood Product Donation. NCI Thesaurus. Code C133267.

Blood or blood product donations intended for transfusion to other than the donor. 